\title{
CHARACTERIZATION OF AIR-WATER TWO-PHASE VERTICAL FLOW BY USING ELECTRICAL RESISTANCE IMAGING
}

\author{
Yingxiang $\mathrm{Wu}^{1 *}$, Hua Li ${ }^{1}$, Mi Wang ${ }^{2}$ and Richard A. Williams ${ }^{2}$ \\ 1. Institute of Mechanics, Chinese Academy of Sciences, Beijing, 100080, China \\ 2. Institute of Particle Science and Engineering, University of Leeds, LS2 9JT, U.K.
}

\begin{abstract}
The characterization of air-water two-phase vertical flow in a $12 \mathrm{~m}$ flow loop with $1.5 \mathrm{~m}$ of vertical section is studied by using electrical resistance tomography (ERT). By applying a fast data collection to a dual-plane ERT sensor and an iterative image reconstruction algorithm, relevant information is gathered for implementation of flow characteristics, particularly for flow regime recognition. A cross-correlation method is also used to interpret the velocity distribution of the gas phase on the cross section. The paper demonstrates that ERT can now be deployed routinely for velocity measurements and this capability will increase as faster measurement systems evolve.

On a étudié par la tomographie à résistance électrique (ERT) la caractérisation de l'écoulement vertical diphasique air-eau dans une boucle d'écoulement de $12 \mathrm{~m}$ avec une section verticale de 1,5 m. En combinant une acquisition de données rapide à un capteur ERT à plan double et un algorithme de reconstruction d'images itératif, des informations pertinentes sont recueillies pour la mise en œuvre des caractéristiques d'écoulement, en particulier pour la reconnaissance du régime d'écoulement. On a également recours à une méthode d'intercorrélation pour interpréter la distribution de vitesse de la phase gaz sur la section transversale. On démontre dans l'article que l'ERT peut désormais couramment s'appliquer pour les mesures de vitesse et cette capacité augmentera à mesure que des systèmes de mesure plus rapides se développeront.
\end{abstract}

Keywords: ERT, gas-liquid two-phase vertical flow, flow regime recognition, velocity measurement

$\mathrm{I}$ $\mathrm{n}$ petroleum industry, multiphase flow of gas and liquid is commonly encountered in the production and transportation of oil and gas, the need for multiphase flow measurement in the oil and gas production has been evident for many years. Multiphase flow measurement has yet to be established as a separate discipline. The complexity in multiphase flow measurement lies in the simultaneous existence of the gas and liquid phases. The interface between the phases (gas-liquid and liquid-liquid) can be distributed in many configurations which are called flow patterns, demonstrate a very important feature of gas-liquid multiphase flows. In single-phase flow in pipes, the design parameters such as pressure drop can be calculated in a relatively straightforward way, while the existence of other phases can bring difficulties in understanding and modeling the flow system. The hydrodynamics of the flow, as well as the flow mechanisms, change significantly from one flow pattern to another.
Process tomography is a discipline which has been a significant growth over the last ten years, and is becoming increasingly promising in the study and application of multiphase flows. This is due to its non-intrusive nature and potential capacity for providing a means of 'looking' inside the detailed local flow information such as volume fraction, the velocity distribution of individual phases and the inter-phase behaviors (Wang and Yin, 2001).

In this paper, electrical resistance tomography (ERT) technique is adopted to study the flow pattern and the velocity distribution in a gas-water two-phase vertical flow (Mann et al., 1999; Wang et al., 2000). In order to use cross correlation technique to perform component velocity measurement, a fast data collection

\footnotetext{
* Author to whom correspondence may be addressed. E-mail address: yxwu@imech.ac.cn
} 
strategy was applied to the dual-plane ERT sensor and an iterative algorithm was used for image reconstruction (Wang, 2002), and much improved velocity profiles of the gas phase in an air/water flow at different flow patterns were reported.

\section{EXPERIMENTAL SET-UP}

All the experiments described in this paper were carried out using the multiphase flow loop made of transparent glass at the Institute of Particle Science and Engineering at University of Leeds, which is a $12 \mathrm{~m}$ gas-liquid flow loop with an inner diameter of $50 \mathrm{~mm}$.

The flow loop can run a maximum superficial liquid velocity of $1 \mathrm{~m} / \mathrm{s}$ with Reynolds number about 58500 and a superficial gas velocity larger than $30 \mathrm{~m} / \mathrm{s}$ with Reynolds number above 100 000. The two-phases of gas and liquid, in terms of flow states of laminar to laminar, laminar to turbulent, turbulent to laminar and turbulent to turbulent, can be created on this test-loop. By controlling the pressure and flow-rates of the gas phase and the liquid phase, many flow patterns, such as bubbly flow, slug flow, churn flow and annular flow, can be created in this device. A tomographic sensor with two sensing planes is also installed in the flow loop in order to obtain flow patterns of two-phase flow.

Tap-water (conductivity $0.370-0.387 \mathrm{mS} / \mathrm{cm}$ ) was used as the liquid phase, and air was introduced into the flow loop, which was measured by a flow-meter at the range of $1-8 \mathrm{~L} / \mathrm{min}$. Measurements were performed at ambient temperature. By controlling the air flowrate at the air inlet, different flow patterns can be generated in the flow loop.

The experiments were performed under different air flowrates to create bubbly flow, slug flow, churn flow, and annular flow regimes. The water flows were scaled with an accumulating tank during the experiments to get water flowrate and mean velocity. Photographs were recorded as visual presentations of these different flow patterns.

\section{THE ERT SYSTEM}

\section{ERT Hardware System}

A P2000 ERT system (Industrial Tomography System Ltd., Manchester) was used for data collection. The so-called adjacent electrode pair strategy (Brown and Segar, 1985) was adopted, using a $10 \mathrm{~mA}$ injection current at $9.6 \mathrm{kHz}$ for flow regime recognition, and a $50 \mathrm{~mA}$ current at $38.4 \mathrm{kHz}$ for cross-correlation calculation. Data collection rates were 23.04 frames per second at the signal frequency of $9.6 \mathrm{kHz}$ and 28.3 frames per second at the signal frequency of $38.4 \mathrm{kHz}$. Both single-plane and dualplane ERT sensors were used in this study. Each ERT sensing plane consisted of 16 titanium-alloy rectangular electrodes $(5 \mathrm{~mm} \times 12 \mathrm{~mm})$.

\section{ERT Sensor Set-Up}

An ERT sensor employing a conductive ring technique was used in this study to overcome the problem caused by some electrodes losing contact with the conductive fluid (Wang et al., 2002). The dual-plane ERT sensor is a core sensing technique in the experiment for implementation of local flow velocities in the two-phase flow. Since the current data collection speed was still limited, we set the distance between the two sensing planes apart to $150 \mathrm{~mm}$. The principle of the dual-plane strategy is based on a 'cross measurement between two correlated electrodes on two sensing planes' instead of plane by plane measurement. In

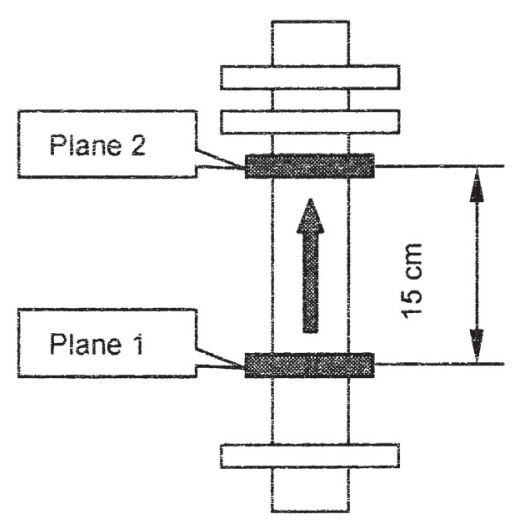

Figure 1. Sensor configuration.

order to reduce the error caused by the point-spread function in SBP (sensitivity coefficient back-projection) algorithm, an iterative algorithm, known as SCG algorithm (Wang, 2002), was utilized to solve the non-linear problem of the electric field. All images used for implementation of local velocities in the paper were reconstructed with the SCG algorithm. The measurements for flow pattern recognition were performed by using one sensing plane at low frequency in order to get maximum data precision.

The dimensions of the dual sensor installation is given in Figure 1.

\section{Flow Parameter Calculation Using ERT}

With conductivity data from ERT, the local volume fraction distribution $\left(\alpha_{C}\right)$ can be determined by applying the Maxwell equation (Maxwell, 1881; Lucas et al., 1999; George et al., 2000):

$$
\alpha_{c}=\frac{2 \sigma_{1}+\sigma_{2}-2 \sigma_{m c}-\sigma_{m c} \frac{\sigma_{2}}{\sigma_{1}}}{\sigma_{m c}-\sigma_{m c} \frac{\sigma_{2}}{\sigma_{1}}+2\left(\sigma_{1}-\sigma_{2}\right)}
$$

where $\sigma_{1}$ is the conductivity of the first phase, $\sigma_{2}$ is the conductivity of the second phase, and $\sigma_{I l l c}$ is the local mixture conductivity distribution.

According to Maxwell, the validity of Equation (1) is limited to small volume fraction, however, various researchers found that Equation (1) produced good agreement with experimental data over a wide range of void fractions (Neale and Nader, 1973; Turner, 1976).

If the second phase is assumed to be non-conductive material, such as air in this study, the above equation can be simplified as following:

$\alpha_{c}=\frac{2 \sigma_{1}-2 \sigma_{m c}}{2 \sigma_{1}+\sigma_{m c}}$

The conductivity of the first phase $\left(\sigma_{1}\right)$ can be found easily with a widely available commercial conductivity meter, while the local mixture conductivity $\left(\sigma_{m c}\right)$ is determined from the pixel conductivity of ERT image.

Due to the ill-posedness of inverse ERT problem and the measurement error, it's a certain level of erroneous to convert the reconstructed conductivity into the void fraction. At the presence of measurement error of $1 \%$, the conductivity error 


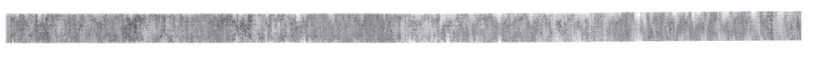

Bubbly flow (superficial water velocity: $0.222 \mathrm{~m} / \mathrm{s}$, superficial air velocity: $0.017-0.025 \mathrm{~m} / \mathrm{s}$ )

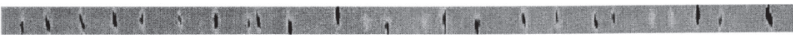

Slug flow (superficial water velocity: $0.017 \mathrm{~m} / \mathrm{s}$, superficial air velocity: $0.008 \mathrm{~m} / \mathrm{s}$ )

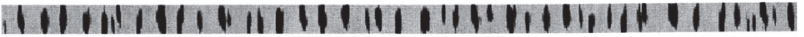

Churn flow (superficial water velocity: $0.195 \mathrm{~m} / \mathrm{s}$, superficial air velocity: $>0.068 \mathrm{~m} / \mathrm{s}$ )

Annular flow (superficial water velocity: $0.536 \mathrm{~m} / \mathrm{s}$, superficial air velocity: >>0.068 m/s)

Figure 2. Flow patterns recognition (black denotes air phase and gray denotes water phase). Bubbly flow (superficial water velocity: $0.222 \mathrm{~m} / \mathrm{s}$, superficial air velocity: $0.017-0.025 \mathrm{~m} / \mathrm{s}$ ) Slug flow (superficial water velocity: $0.017 \mathrm{~m} / \mathrm{s}$, superficial air velocity: $0.008 \mathrm{~m} / \mathrm{s}$ ) Churn flow (superficial water velocity: $0.195 \mathrm{~m} / \mathrm{s}$, superficial air velocity: $>0.068 \mathrm{~m} /$ s) Annular flow (superficial water velocity: $0.536 \mathrm{~m} / \mathrm{s}$, superficial air velocity: >>0.068 m/s).

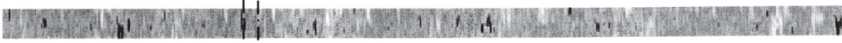 $\longrightarrow \mathrm{i} \leftarrow$ WWWUW}

Bubbly flow (superficial water velocity: $0.547 \mathrm{~m} / \mathrm{s}$, superficial air velocity: $0.025 \mathrm{~m} / \mathrm{s}$ )

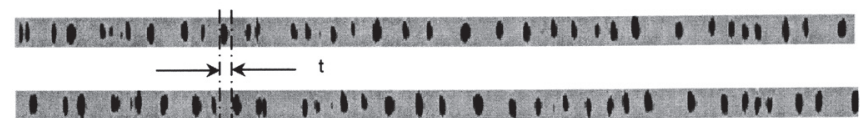

Churn flow (superficial water velocity: $0.223 \mathrm{~m} / \mathrm{s}$, superficial air velocity: $>0.068 \mathrm{~m} / \mathrm{s}$ )

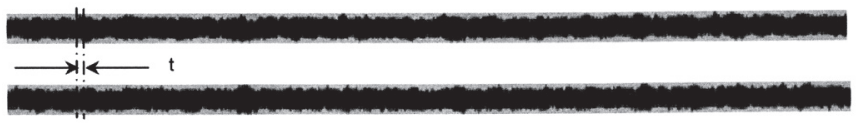

Annular flow (superficial water velocity: $0.743 \mathrm{~m} / \mathrm{s}$, superficial air velocity: $>>0.068 \mathrm{~m} / \mathrm{s}$ )

Figure 3. Cross-correlation between two images obtained from dualplane ERT sensor Bubbly flow (superficial water velocity: $0.547 \mathrm{~m} / \mathrm{s}$, superficial air velocity: $0.025 \mathrm{~m} / \mathrm{s}$ ) Churn flow (superficial water velocity: $0.223 \mathrm{~m} / \mathrm{s}$, superficial air velocity: $>0.068 \mathrm{~m} / \mathrm{s}$ ) Annular flow (superficial water velocity: $0.743 \mathrm{~m} / \mathrm{s}$, superficial air velocity: $>0.068 \mathrm{~m} / \mathrm{s}$ ).

could be up to $10 \%$ subjecting to the magnitude of conductivity charge (Wang et al., 1999).

The local axial velocity can be obtained by applying the crosscorrelation technique to determine the speed of moving profiles. The basic function of the cross-correlation technique is to find the time offset between two signals where the similarities are most obvious. These signals can be any value and are not limited to quantitative conductivity data. This goal is to find a transition time $\tau$ that corresponds to the minimum difference $(\varepsilon)$. This can be achieved by using the least square criterion as the following equation:

$\varepsilon_{x y}^{2}(\tau)=\min \lim _{T \rightarrow \infty} \frac{1}{T} \int_{-T}^{T}\left[x(t)-y(t-\tau)^{2}\right] d t$
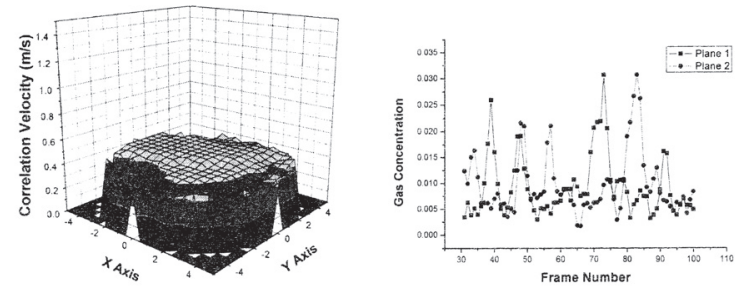

(a) Bubbiy flow (superficial water velocity: $0.141 \mathrm{~m} / \mathrm{s}$, superficial air velocity: $<0.008 \mathrm{~m} / \mathrm{s}$ )
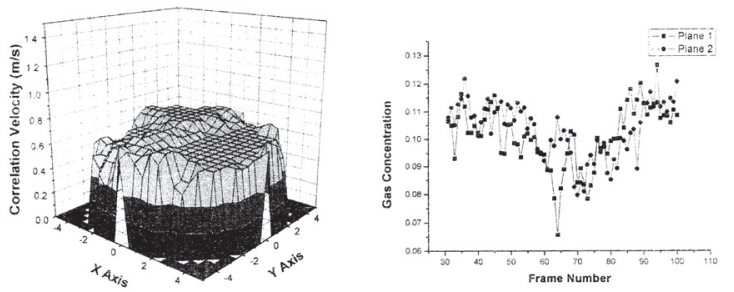

(b) Churn flow (superficial water velocity: $0.419 \mathrm{~m} / \mathrm{s}$, superficial air velocity: $>0.068 \mathrm{~m} / \mathrm{s}$ )
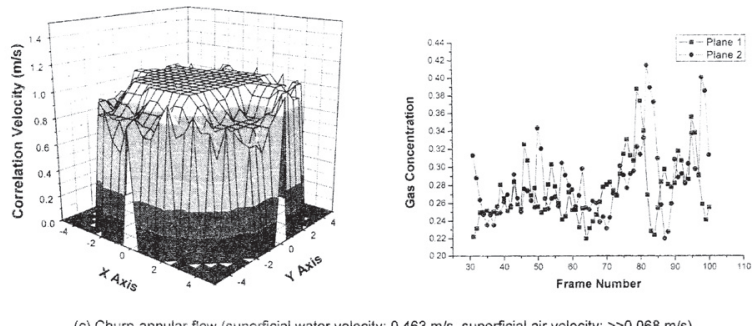

(c) Chum-annular flow (superficial water velocity: $0.463 \mathrm{~m} / \mathrm{s}$, superficial air velocity: $\gg>0.068 \mathrm{~m} / \mathrm{s}$ )

Figure 4. Correlation local velocity distributions and mean cross-section gas concentration at different flow patterns (a) Bubbly flow (superficial water velocity: $0.141 \mathrm{~m} / \mathrm{s}$, superficial air velocity: $<0.008 \mathrm{~m} / \mathrm{s}$ ) (b)

Churn flow (superficial water velocity: $0.419 \mathrm{~m} / \mathrm{s}$, superficial air velocity: $>0.068 \mathrm{~m} / \mathrm{s}$ ) (c) Churn-annular flow (superficial water velocity:

$0.463 \mathrm{~m} / \mathrm{s}$, superficial air velocity: $>>0.068 \mathrm{~m} / \mathrm{s}$ )

where $x, y$ are the original signals of conductivity at each imaging cross section respectively, $\varepsilon$ is the error function which gives the transition time $\tau$ when the expression takes a minimum value. Replacing the integral by partial summation, Equation (3) can be expressed in discrete form:

$\varepsilon_{k}^{2}(I l)=\sum_{m=1}^{N}\left[x_{k}(I I l)-y_{k}(I I l-I l)\right]^{2}$

where $N$ is sample length, $n$ is the sample offset number and $k$ is the number to indicate different pixels on the cross-section. In the computation, $N$ should be selected according to the distance between the dual-plane ERT sensors and the maximum and the minimum velocity of the flow. In this study, only the axial velocity is considered, and when $N$ is selected properly, there is a strong correlation between planes.

\section{EXPERIMENT RESULTS}

\section{Flow Pattern Recognition}

Flow pattern recognition was obtained with data from the singleplane ERT sensor (plane 1 in Figure 1). By stacking part of SBP tomograms in temporal order within the vertical axial plane, gasphase and liquid-phase distribution and their dynamical varying processes (flow processes) in the pipe can be clearly demonstrated. Flow pattern variations with air flowrates, as illustrated in Figure 2, were visualised. 


\section{FLOW VELOCITY MEASUREMENT}

To demonstrate the use of cross correlation in obtaining the velocity profile of a multiphase flow, some stacked images from different air flowrates are given in Figure 3. The correlation between two images taken from different positions is obvious. It demonstrates the dual-plane mode at 28.3 dual-frames/sec is able to manage the velocities at the demonstrated mean air flowrates.

The gas-phase velocity converted from the cross-correlation results can be calculated by:

$v=\frac{\Delta s}{\Delta t}=\frac{L F_{s}}{n_{k}}$

where $L$ is the distance between two sensor planes, $n_{k}$ is the number of $n$ when it makes Equation (3) or (4) take the minimum value, $F_{S}$ is the sampling frequency.

According to other researchers (Beck and Plaskowski, 1986; Loh, 1998), the minimum acquisition time, $\delta$, can be taken as twice the product of the minimum transit time of the fluid, $\tau$, and the fractional velocity discrimination, $\kappa$. By rearranging this gives the following

$\kappa=\frac{\delta}{2 \tau}$

The minimum transit time of the fluid, $\tau$, is given by

$\tau=\frac{L}{V}$

When the distance $L$ is $15 \mathrm{~cm}$, the axial velocity $v$ is $1 \mathrm{~m} / \mathrm{s}$ and the sampling frequency is $28.3 \mathrm{fps}$, the fractional velocity discrimination $\kappa$ is about 0.12 . A higher sampling frequency is needed to increase the discrimination.

By applying the cross-correlation procedure to a data set of 1000 -frame of tomographic images, that were acquired from the air/water two-phase vertical pipe flow, an evident correlation was found for the similar flow information at some corresponding pixels of the dual-sensing rings. Figure 4 shows the velocity distribution, resulted from the cross-correlation implementation, for a bubbly flow and a churn flow. The superficial velocities estimated in the experiments are $0.141 \mathrm{~m} / \mathrm{s}, 0.419 \mathrm{~m} / \mathrm{s}$ and 0.463 $\mathrm{m} / \mathrm{s}$ for water.

\section{DISCUSSIONS AND CONCLUSIONS}

From the main results of Figures 2, 3 and 4, some useful information and interesting phenomena can be found for both gas-liquid two-phase flows in a vertical pipe and ERT technique, viz.:

First, the ERT technique is a suitable means for detecting the flow patterns of gas-liquid multiphase flow in a vertical pipe. With a fast data collecting protocol and an effective iterative image reconstruction algorithm, gas-phase and liquid-phase distribution and their dynamic variations in the pipe can be clearly quantified (Figure 2).

Secondly, the time of cross-correlation can reveal the velocity magnitude of the interface of gas-phase and liquid-phase as shown in Figure 3 where the cross-correlation time intervals are different. Based on the time interval (ERT data frames), the mean velocity of gas-liquid two-phase can be estimated. This may be important in the on-situ monitor of industrial processes.
Thirdly, we can see that as gravity acts in the axial direction giving symmetry across the pipe cross-section. Flow patterns tend to be somewhat more stable, but with slug and churn flows, oscillations and bubble roll in the flow can occur to destroy the symmetry. The degree of the cross-correlation of the flow state is good for bubbly flow and annular flow, but not so good for churn flow (Figure 4). This can also be proven during the crosscorrelation procedure. In a bubbly or an annular flow, the crosscorrelation graphics can be obtained almost on every pixel, but only partially for churn flows.

Fourthly, the velocity on the central part of the pipe is larger than that on the edge of the pipe at any flow pattern. For a churn flow (Figure 4.b), large air bubbles rise upwards asymmetrically, which causes the distribution of velocities on a section of the flow loop also to be asymmetrical. While for a bubbly flow or an annular flow, it is almost symmetrical. As the amount of gas is increased the coalescence of smaller air bubbles forming larger bubbles gradually concentrates on the core of the pipe to transit to an annular flow at the end of the pipe.

Lastly, for a churn flow or an annular flow, as the velocity is relatively high, the sampling frequency should be high, otherwise large errors will arise in the implementation. For a sampling frequency of $28.3 \mathrm{fps}$, the fractional velocity discrimination, , is about 0.12 at the axial velocity of $1 \mathrm{~m} / \mathrm{s}$. The step changes shown in Figure 4 reflect the implementation errors. More noise points occur on the edge of the pipe with increasing gas content. For obtaining accurate value of flow parameters, much more care should be taken both on ERT hardware and software improvement, such as increasing the sampling frequency, reducing noise influence, developing better correlation algorithm to describe the three-dimensional velocity distribution of the flow field (Ma et al., 2003).

\section{ACKNOWLEDGMENTS}

The authors gratefully acknowledge the supports of Royal SocietyChinese Academy of Sciences (under Joint Project: Q783), CAS \& CNOOC (under grant KJCX2-SW-L03), and National 863 Project (under the project number 2001AA413210).

\section{NOMENCLATURE}

$F_{S} \quad$ sampling frequency, $(\mathrm{Hz})$

$L^{s} \quad$ distance between two sensor planes, (m)

$n \quad$ sample offset number

$N \quad$ sample length

$T, t \quad$ time, (s)

$v \quad$ velocity, $(\mathrm{m} / \mathrm{s})$

$x, y \quad$ original signals of conductivity, $(\mathrm{mS} / \mathrm{cm})$

\section{Greek Symbols}

$\alpha_{c} \quad$ volume fraction distribution

$\delta \quad$ minimum acquisition time, (s)

$\varepsilon \quad$ minimum difference

$\kappa$ fractional velocity discrimination

$\sigma \quad$ conductivity, $(\mathrm{mS} / \mathrm{cm})$

$\tau \quad$ transition time, $(\mathrm{s})$

\section{Subscripts}

$k \quad$ pixel number

$m \quad$ mixture 


\section{REFERENCES}

Beck, M. S. and A. Plaskowski, "Cross Correlation Flowmeters - Their Design and Application”, Adam Hilger, Bristol, UK (1986).

Brown B.H. and A.D. Segar, "Applied Potential Tomography: Data Collection Problems”, Proc. IEE Int. Conf. on Electric and Magnetic Field in Medic. and Biolo., 79-82 (1985).

George, D.L., J.R. Torczynski, K.A. Shollenbeger, T.J. O’hen and S.L. Ceceio, "Validation of Electrical-impedance Tomography for Measurements of Material Distribution in Two-phase Flows", Int. J. Multiphase Flow 26, 549-581 (2000).

Loh, W. W., "Real-time Monitoring of Drilling Cuttings Transport Using Electrical Resistance Tomography”, Ph.D Thesis, UMIST, pp. 103-104 (1998).

Lucas, G.P., J. Cory, R. Waterfall, W.W. Loh and F.J. Dickin, "Measurement of the Solids Volume Fraction and Velocity Distributions in Solid-liquid Flows Using Dual-plane Electrical Resistance Tomography”, J. Flow Meas. Instrum. 10, 249-258 (1999).

Ma, Y., N. Holloday, Y. Dai, M. Wang, R.A. Williams and G. Lucas, "A High Performance Online Data Processing EIT System", Proc. of 3rd World Congress on Industrial Process Tomography, Banff, AB, Sep. 2-5, (2003), pp. 27-32.

Mann R., M. Wang, A.E. Forrest, P.J. Holden, F.J. Dickin, T. Dyakowski and R.B. Edwards, "Gas-liquid and Miscible Liquid Mixing in a Plant-scale Vessel Monitored Using Electrical Resistance Tomography”, Chem. Eng. Comm. 175, 39-48 (1999).

Maxwell, J.C., "A Treatise on Electricity and Magnetism”, Clarendon Press, Oxford, UK(1881).

Neale, G.H. and W.K. Nader, "Prediction of Transport Process within Porous Media: Diffusion Flow Processes within an Homogeneous Swarm of Spherical Particles”, AICHE J. 19, 112-119 (1973).

Turner J.C.R., "The Electrical Conductance of Liquid Fluidised Beds of Spheres”, Chem. Eng. Sci., 31, 487-492 (1976).

Wang M., "Inverse Solutions for Electrical Impedance Tomography Based on Conjugate Gradients Methods”, Meas. Sci. Technol. 13, 101-117 (2002).

Wang M., A. Dorward, D. Vlaev and R. Mann, "Measurements of Gas-liquid Mixing in a Stirred Vessel Using Electrical Resistance Tomography (ERT)", Chem. Eng. J. 77, 93-98 (2000).

Wang M., R. Mann and F.J. Dickin, "Electrical Resistance Tomographic Sensing Systems for Industrial Applications", Chem. Eng. Comm. 175, 49-70 (1999).

Wang M. and W. Yin, "Measurements of the Concentration and Velocity Distribution in Miscible Liquid Mixing Using Electrical Resistance Tomography”, Trans. IChemE. 79, Part A, 883-886 (2001).

Wang M., W. Yin and N. Holliday, "A Highly Adaptive Electrical Impedance Sensing System for Flow Measurement”, Meas. Sci. Technol. 13, 1884-1889 (2002).

Manuscript received January 20, 2004; revised manuscript received September 17, 2004; accepted for publication February 8, 2005. 